\title{
Congenital cleft sternum
}

\author{
A. EIJGELAAR and J.H. BIJTEL \\ Department of Thoracic Surgery of the Surgical Clinic, and Department of Embryology of the \\ Anatomical Laboratory, State University, Groningen, The Netherlands
}

The embryonic development of the sternum is discussed in an effort to explain the pathogenesis of cleft sternum (fissura sterni congenita). The treatment of one patient with such an anomaly is described. The operative indication, operative technique, and timing of the correction are discussed in some detail.

Total or partial fissure in the middle of the sternum (cleft sternum or fissura sterni congenita) is a rare congenital anomaly.

Absence of skeleton in the front part of the chest wall gives rise to a severely paradoxical movement of this part of the thorax (Figs 1 and 2). Moreover, the pulsations of the heart and large vessels are clearly visible because they are covered only by soft tissues.

The anomaly is caused by a disturbance in embryonic development, of unknown origin. This disturbance in embryonic development may lead to various degrees of cleft sternum (de Groot and Huizinga, 1954):

1. The presence of non-fused, ossified episternalia ; 2. Total or partial cleft sternum. In total sternal fissure the two halves of the sternum are entirely separated. In the more severe cases of partial fissure, only the xiphoid process is fused, and this

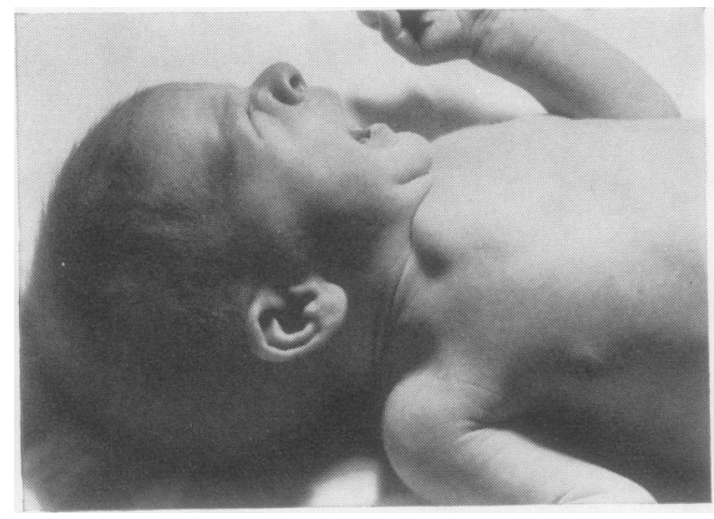

FIG. 1. Protruding soft parts in expiration.

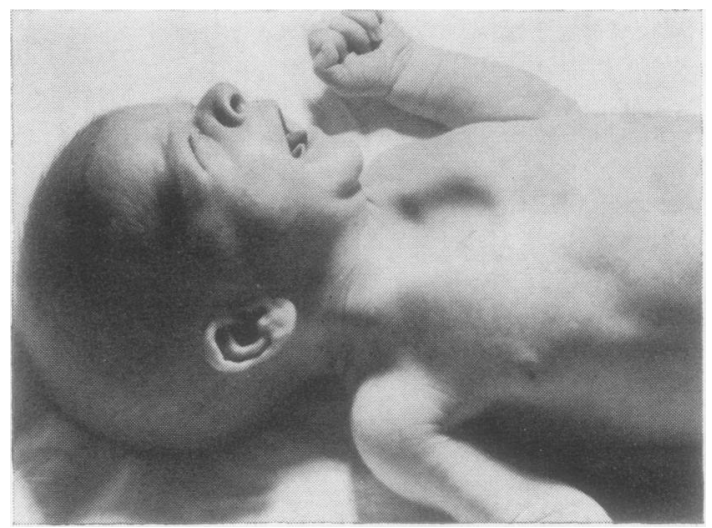

FIG. 2. Retraction of soft parts in inspiration.

fissure takes the shape of a triangle with the apex in a caudal direction;

3. A very rare situation is non-fusion of the caudal portion of the sternum, which produces a triangular defect with the apex in a cranial direction. Congenital perforations of the sternal body also come under this heading;

4. A cleft xiphoid process is a common anomaly; in fact it is likewise a modality of non-fusion of the caudal portion of the sternum.

\section{EMBRYOLOGICAL INTRODUCTION}

For an understanding of the pathogenesis of these sternal anomalies the development of the human embryo has first to be considered.

Until the beginning of the third week, the embryonic primordium lies practically flat on the yolk sac. In the course of this week the three germ 
layers become visible - the ectoderm and the entoderm with the notochord and the mesoderm in between (Fig. 3). At the same time the head part of the embryo begins to rise above the surface and to detach itself, soon followed by the tail part, so that a cranial and a caudal fold are formed.

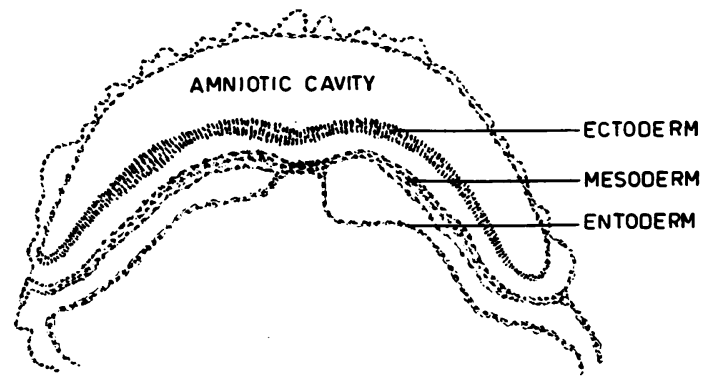

FIG. 3. Transverse section through an embryo in the third week. Development of the three germ layers.
Simultaneously, the future dorsal part of the embryo begins to bulge upwards into the amniotic cavity. These processes continue during the fourth week (Fig. 4).

Towards the end of the third week the paraxial mesoderm begins to show metametic segmentation. On either side of the notochord somites are formed. They are linked by the intermediary mesoderm with the more laterally located unsegmented lateral plate mesoderm. Small cavities originate in the latter and unite to form the secondary body cavity or intra-embryonic coelom.

A short time later the latter joins with the extraembryonic coelom. The formation of the coelom causes the lateral plate mesoderm to divide into two layers-a parietal or somatic and a visceral or splanchnic layer, which at this stage arrange themselves against the ectoderm and the entoderm respectively (Fig. 5).

The part of the body wall lateral to the somites (the somatopleure) has meanwhile started to fold,

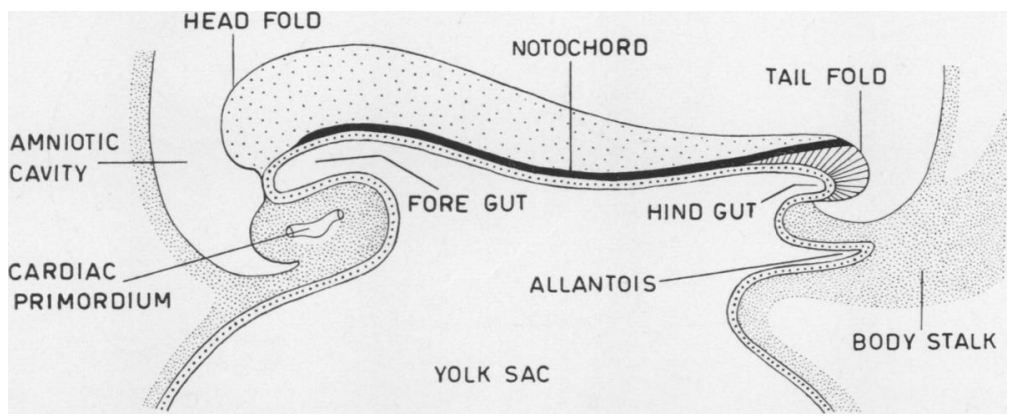

FIG. 4. Schematic representation of a median section through an embryo at the beginning of the fourth week.

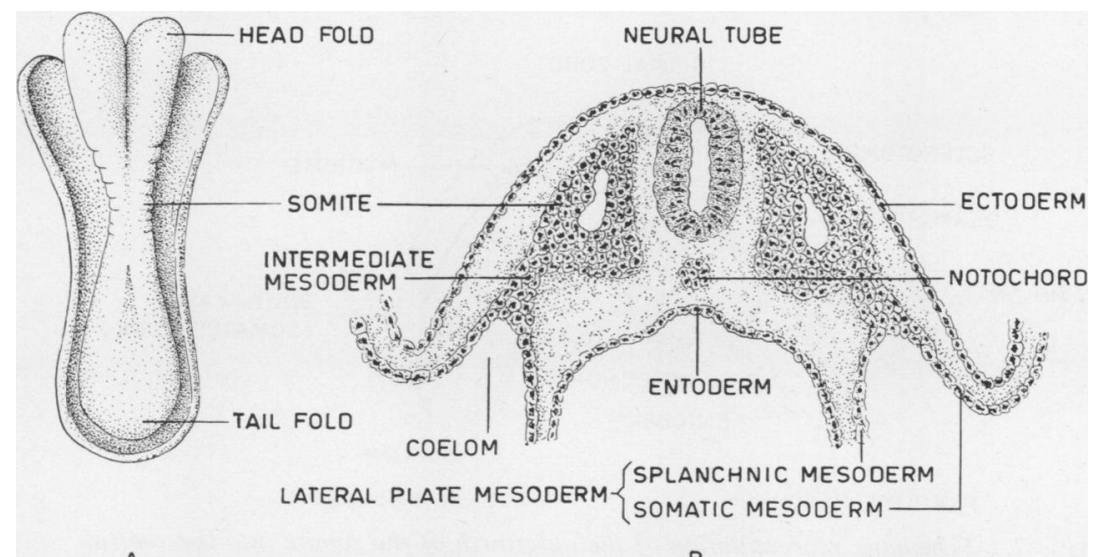

A

$B$

FIG. 5. A. Embryo at the beginning of the fourth week. B. Transverse section through the same embryo. 
at first ventrally and then also medially. At the level of the umbilicus it encloses, among other structures, the still wide communication between the future intestine and the yolk sac.

As the embryonic dimensions increase in the subsequent weeks, the thoracic and abdominal parts of the body wall-cranial and caudal to the umbilicus respectively-become elongated; the elongation of the former considerably exceeds that of the latter (Fig. 6).

The body wall is very thin at this stage and consists of the ectodermal layer with the very thin parietal mesodermal layer against its inner side. The latter layer lines the thoracic and the abdominal cavity, and thus forms the parietal pleura and the parietal peritoneum as well as the pericardium. Other components of this part of the body wall migrate ventrally from the dorsally located somites and penetrate between the two somatopleural layers mentioned above. For the intrinsic thoracic region these components are or the left and on the right:

1. The primordium of the ribs and of the corre $\stackrel{\Phi}{\varrho}$ sponding intercostal muscles;

2. The connective tissue (corium or dermis), which is to line the internal surface of the ectodermat portion (epidermis) of the future skin (cutis); andw 3. The subcutaneous tissue (hypodermis), which ist to connect the skin with the underlying tissue.

The development of the last-mentioned com $N$ ponents of the chest wall begins during the fourthi week. At this stage the somites start to differentiateo into a medioventral sclerotome which, in this area, supplies the material for the vertebrae as well as that for the ribs, and a more dorsolatera dermomyotome which furnishes connective tissu

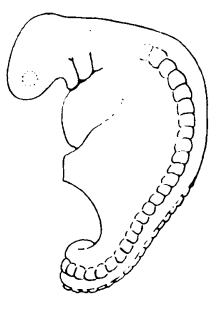

A

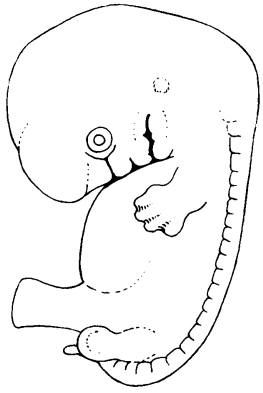

B

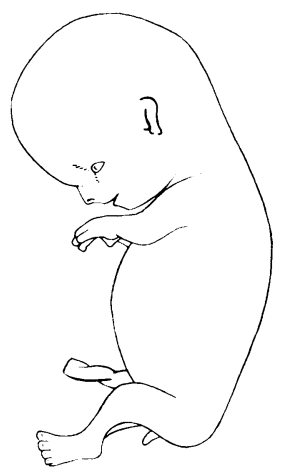

C

FIG. 6. Development of the ventral body wall in three stages: A. 26 days, crownrump length $3.5 \mathrm{~mm}$; B. 40 days, crown-rump length $13.4 \mathrm{~mm}$.; C. 60 days, crown-rump length $30.7 \mathrm{~mm}$.

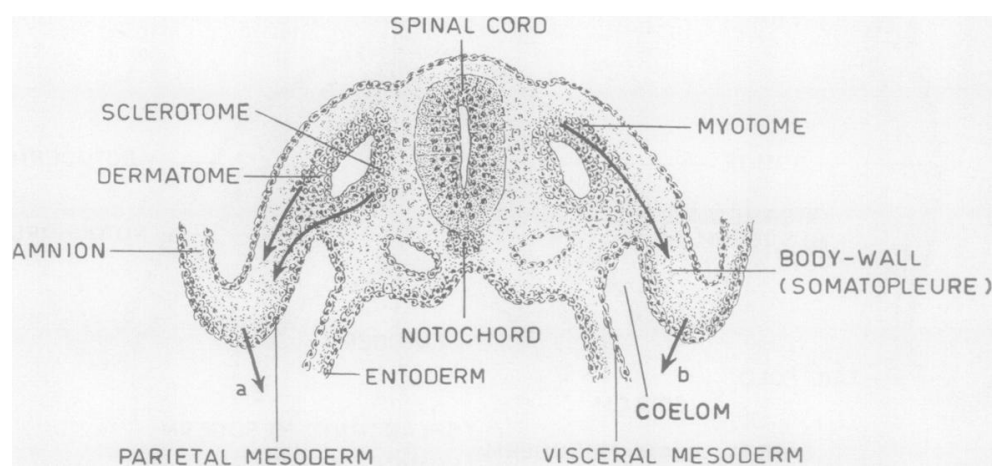

FIG. 7. Schematic representation of the outgrowth of the somite into the ventral body wall. The arrows in sclerotome, dermatome, and myotome mark the direction in which the tissues migrate. Arrows $a$ and $b$ mark the direction in which the body wall grows out. 
for such parts as the dermis and hypodermis (dermatome) and muscular tissue for segmented muscles (myotome) (Fig. 7).

It is not until the sixth week of human embryonic development that the 'anlage' of the sternum becomes visible. It appears in the form of two mesenchymal bands which arise on either side in the ventral body wall far from the mid-line. That the 'anlage' is paired is linked up with the fact that the young embryo initially lies flat on the yolk sac. In all animal species, whose embryos develop in this way, the sternum originates from two separate mesenchymal bands. These sternal bands are formed independently of the ribs, which arise from the sclerotomes. At this early stage the bands show no connection with the distal ends of the primordia of any of the separate ribs. In this context we refer to Whitehead and Waddell (1911), Hommes (1921), and Gladstone and Wakeley (1932), who examined mammalian embryos for this purpose. Whitehead and Waddell and Gladstone and Wakeley examined young human embryos as well. In human embryos the two mesenchymal sternal bands are present in the sixth week of development (Brandt, 1949 ; Patten, 1968). In a human embryo of $10.5 \mathrm{~mm}$., examined by Whitehead and Waddell, no costal primordium directly reached as far as any of the sternal bands.

These facts were convincingly confirmed by Fell (1939), who experimented on chick embryos, and by Chen (1952a, b, 1953), who made similar experiments on mouse embryos. Both investigators were able to demonstrate that the sternum evolves from two mesenchymal condensations, which not only develop without intermediation of the ribs but are capable, in vitro, of moving towards the median plane and fusing there without costal intervention.

These findings justify rejection of the view that the sternal bands develop as a result of the union of the successive costal blastemas. The reconstructions by which Müller (1906) documented this view are undoubtedly of importance. The stages of development of the embryos, however, from which she made these reconstructions were too advanced to allow conclusions concerning the first 'anlage' of the human sternum.

In the development of the sternum, the 'anlage' of the manubrium requires further consideration.

Apart from the sternal bands a few blastemas of different nature participate in this anlage. In the human embryo, too, these structures are visible in certain developmental stages as mesenchymal blastemas. Between the ventral ends of the primordia of the left and the right clavicle, a pair of blastemas has been observed by Eggeling (1906), Reiter (1942), and Klima (1968). They described them as 'suprasternal structures'. These two structures are localized in line with the cranial ends of the two sternal bands, with which they fuse afterwards. In addition, an unpaired mesenchymal condensation is localized between the caudal ends of the suprasternal structures; this was described by Eggeling, Reiter, and Klima as a 'precostal process'. Klima depicted these three structures in sections through embryos of 21 and $27 \mathrm{~mm}$. They are visible during a short time only.

The development of the manubrium thus involves the blastemas described as suprasternal structures and the precostal process, as well as the cranial parts of the sternal bands situated at the level of the first rib (Fig. 8).

With regard to the development of the manubrium sterni it may be pointed out that the suprasternal structures are sometimes homologized with special elements of the coracoid, i.e., with components of the shoulder girdle. In any case their origin lies in a region which differs from the region of origin of the sternal bands.

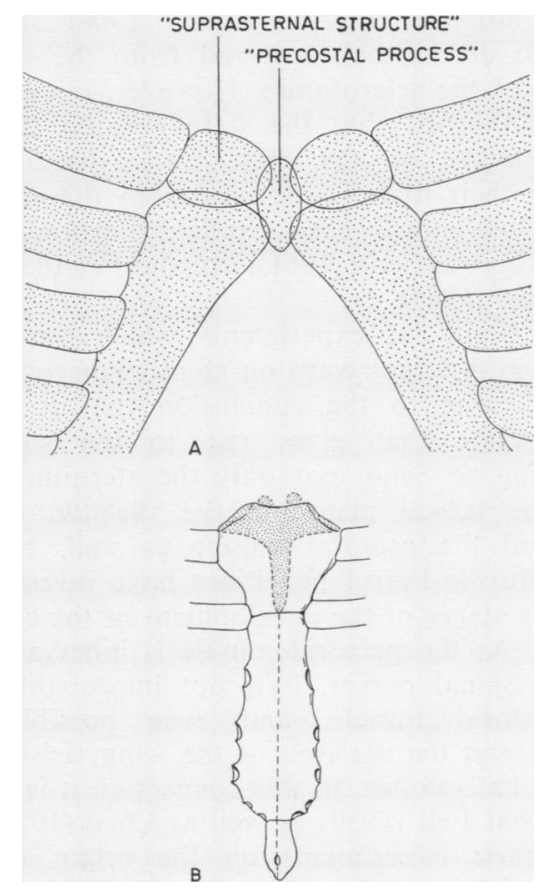

FIG. 8. Development of the sternum: A. After Klima (1968); B. After Reiter (1942). 
The origin of the precostal process is even more difficult to explain.

Both sternal primordia, each consisting of a sternal band with a suprasternal structure at its cranial end, have their first contact at the cranial end of the thorax. Klima demonstrates the start of the fusion in a reconstruction of the sternum of an embryo of $17 \mathrm{~mm}$. This implies that the fusion starts in about the seventh week. At this stage each of the sternal bands has begun to fuse with its adjoining suprasternal structure. As the fusion of the left and the right sternal primordium proceeds in a caudal direction the more ventrally localized unpaired precostal process is enclosed by them. Klima depicts this enclosure in sections of embryos of 21 and $27 \mathrm{~mm}$. The fusion of the more caudal parts of the sternal bands is completed during the ninth or tenth week (Müller, 1906 ; Patten, 1968).

The question which now arises concerns the source of the material for the sternal body. In view of what has been said about the manubrium it is plausible, not only on embryological but also on phylogenetic grounds, that the material of which the sternum is made up originates from two different sources.

In the older view the sternal bands, as a product of union of the ribs (Müller, 1906), are supposed to derive their material from the somites by way of the sclerotomes. However, since it has been established that the sternal bands develop independently of the ribs, it is questionable whether their material derives from the somites. This question has been explicitly expressed by such authors as Seno (1961), Murillo-Ferrol (1963), and Pinot (1969).

As a result of experiments which were performed in different ways on chick embryos, these authors came to the conclusion that it is the lateral plate that gives rise to the sternum. According to Seno, not only the sternum arises from the lateral plate but the skeleton of the wing and the pectoral muscle as well. Neither Seno, Murillo-Ferrol nor Pinot have investigated the early stages of the development of the cervical somites. As the pectoral muscle is innervated by cervical spinal nerves, it is not improbable that the pectoral muscle, and even possibly the sternum and the skeleton of the wing, arise from the cervical somites. In this connection it is worth noting that Fell (1939) as well as Chen (1952a, b) began their experiments on the origin of the sternum by a study of its normal development. Both Fell and Chen pointed out that the development of the sternal bands-which occurs in the region where lateral plate mesoderm material is available-is preceded and accompanied by general tissue migration from the dorsolateral body wall in a ventral direction. They do not comment on the origin of this material. That this may originate from somites seems not unlikely, but experimental studies are required before this question can be definitely answered.

The above-mentioned data on the embryonic development of the sternum make it clear that sternal anomalies can be divided into two principal groups, as indicated by de Groot and Huizinga (1954):

a. The most common type of fissure is that in the cranial part of the sternum. Non-fusion of the blastemas described as suprasternal structures and as the precostal process prevents the union of the cranial ends of the sternal bands. This results in a partial sternal fissure. If the union of the sternal bands fails at full length this abnormal course of development leads to a total sternal fissure.

b. Exceedingly rare is the isolated fissure in the caudal portion of the sternum without other congenital anomalies. This anomaly is to be ascribed to premature termination of an otherwise normal course of development. Central perforations in the sternal body and xiphoid fissures come under this heading.

As congenital sternal fissures are rare, its therapeutic consequences are less well known. The gravely abnormal mobility of the anterior chest

\section{T A B L E}

OPERATIONS FOR CONGENITAL STERNAL FISSURE FROM THE LITERATURE

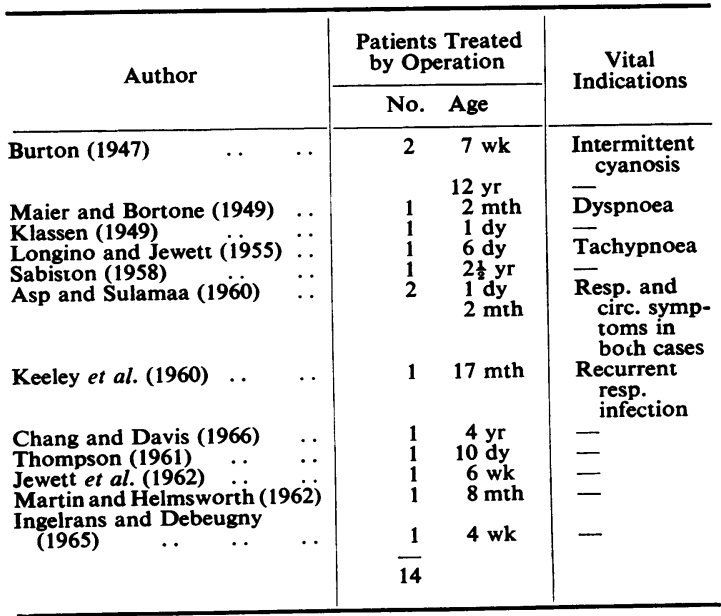


wall and the often visible pulsations of the heart and large vessels impress the observer as an abnormality which calls for surgical treatment without delay.

The available literature shows that the anomaly was corrected within two months of birth in 9 out of 14 cases (Table). At this age the flexibility of the chest wall allows easy approximation of the two sternal halves (Maier and Bortone, 1949; Longino and Jewett, 1955). In 1958, Sabiston described a technique for correction of a congenital sternal fissure at a slightly later age. This calls for subperichondral incision of the first four or five pairs of ribs. The resulting increase in the mobility of the two sternal halves with regard to the ribs facilitates closure of the sternal fissure (Figs 9 and 10).

In this manner Sabiston corrected a congenital sternal fissure in an infant aged 2 years and 6 months, and Chang and Davis (1966) used the technique successfully in a child aged 4 years.

In an effort to ensure minimum reduction of the thoracic volume, we used the Sabiston technique to correct a congenital sternal fissure in a 6-week-old patient.

\section{CASE HISTORY}

Patient E. L. was born at term on 30 March 1967 after an uneventful pregnancy. There was no dyspnoea and no cyanosis. Immediately after birth it was noted that the anterior chest wall showed gravely paradoxical movements (Figs 1 and 2). The child was admitted to the Groningen Surgical Clinic on 17 April 1967. General examination disclosed no special findings. The sternum showed an almost total fissure; in addition there was diastasis of the rectus abdominis muscles between the xiphoid process and the umbilicus.

On palpation the two clavicles could be followed as far as the edges of the sternal defect. The caudal ends of the two sternal halves were fused medially over a distance of about $1 \mathrm{~cm}$. The chest radiograph, obtained after marking the lateral edges of the sternal defect with lead wires, showed the features presented in Figure 11.

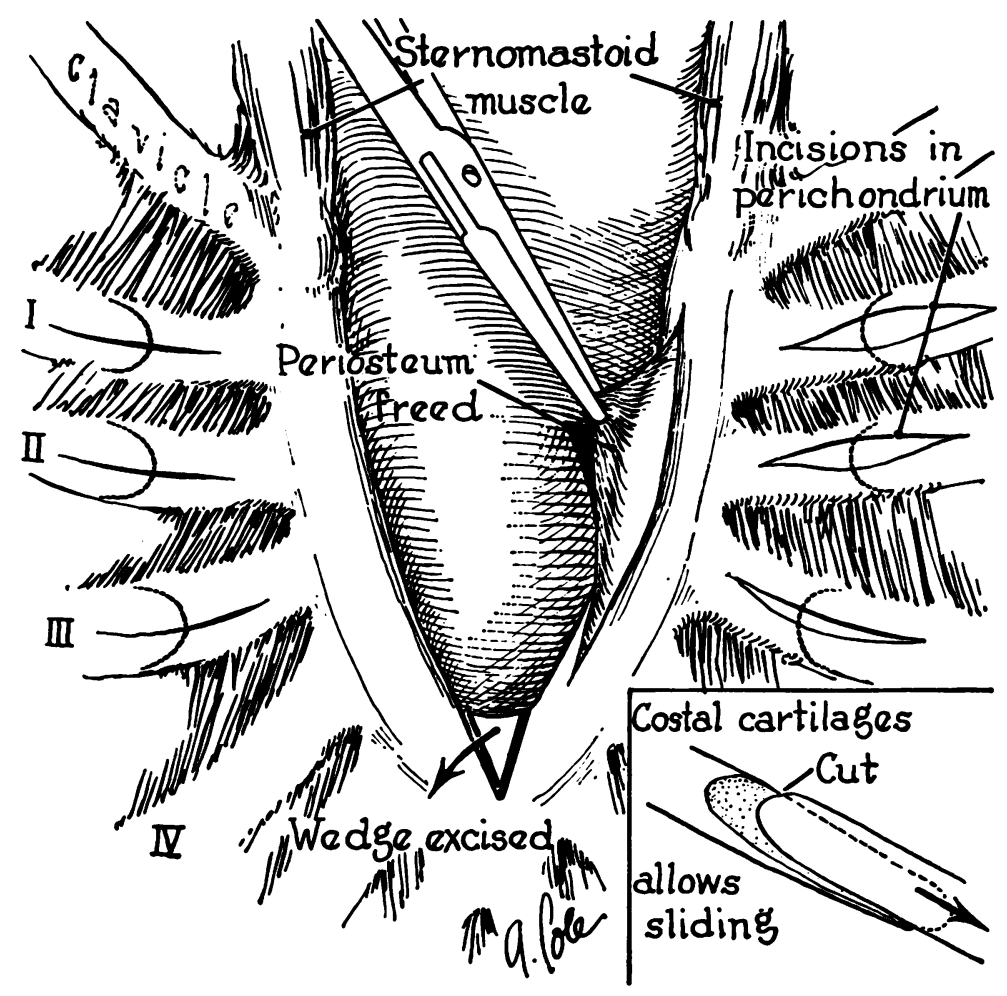

FIG. 9. Preparation of the operative field. (From Sabiston, D. C., J. thorac. Surg., 35, 118, 1958.) 


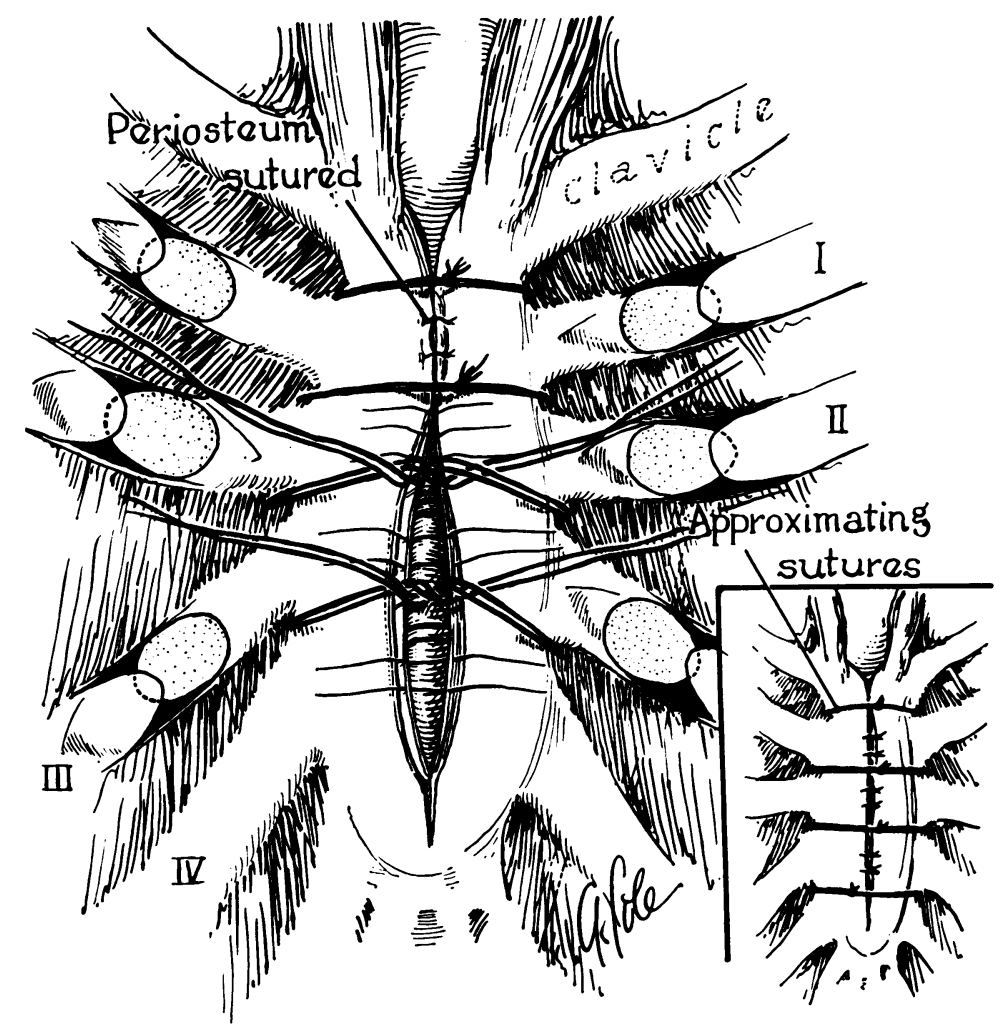

FIG. 10. Sternal halves approximated; evident gain of space by the incision in the costal cartilage. (From Sabiston, D. C., J. thorac. Surg., 35, 118, 1958.)

Diarrhoea and purulent conjunctivitis made it necessary to postpone the operation until 5 May 1967. At that time the two sternal halves were approximated, as indicated by Sabiston (Figs 9 and 10). The post-operative course was uneventful apart from some slightly delayed healing of the wound.

A few weeks later, venous congestion in the right arm was observed when the patient was resting on the right side (costoclavicular compression?). This venous congestion has not been observed since the child's discharge from the clinic.

When seen two years after the operation the child had grown satisfactorily. The distal part of the sternum, however, shows an anomaly that causes a cleft-like excavation of the chest wall (Fig. 12). Probably a dissociation in the speed of the growth of the original caudal sternal bridge is the reason for this anomaly.

\section{DISCUSSION}

Operative correction of a sternal fissure, total or partial, is technically feasible in neonates as well as in slightly older infants. In a number of the 14 cases listed in the Table the operation was pep. formed on a vital indication, e.g., attacks of cyanosis, dyspnoea, tachycardia or recurren respiratory infections (Burton, 1947 ; Longino and Jewett, 1955 ; Martin and Helmsworth, 1962) In the other patients the operative indication was determined chiefly by the paradoxical movement of the anterior chest wall. However, the extent t8 which an apparently paradoxical movement likely to produce vital symptoms is often unu certain shortly after birth.

Attacks of cyanosis in neonates and recurrem respiratory infections in somewhat older infans constitute a vital indication for correction of the anomaly. Even in neonates, determination of arterial and venous blood gas values supplies $\bar{Q}$ measurable indication of the influence of the anomaly on respiration and circulation.

However, when a patient with a congenitaे cleft sternum shows no serious symptoms eithe्d shortly after birth or later, the necessity fơ 


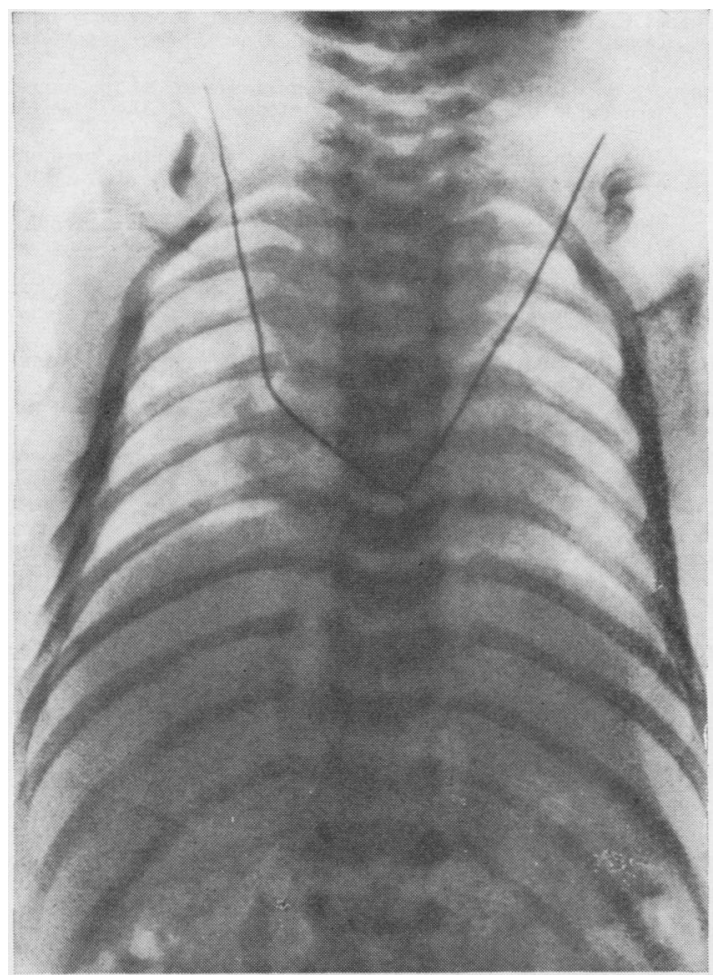

FIG. 11. Chest radiograph in which the retraction in Fig. 2 is outlined by lead wire markers.

operative correction remains a moot point. This question is the more urgent because the literature contains several reports on adults with a congenital sternal fissure which had remained asymptomatic (Szenes, 1922 ; Greig, 1926 ; de Groot and Huizinga, 1954 ; Meissner, 1964).

Magan (1949) and Pfeiffer (1956), for example, described a woman with a congenital sternal fissure who had had several uneventful pregnancies. The patient referred to by Pfeiffer had in fact a total fissure. The operative indication in these patients would therefore have been cosmetic. This is not a reason to omit the operation, but its risk must seriously be taken into consideration.

The literature shows that correction of a congenital sternal fissure carries a small risk: 12 of the 14 operations remained free of complications. Two patients died after the operation, but in both there was a complication in the form of cervicofacial angiomatosis, with angiomas also in the proximal part of the trachea. Probably as a result of the intubation, the intratracheal angiomas bled abundantly, as a result of which the patients died immediately after the operation (Jewett, Butsch, and Hug, 1962 ; Ingelrans and Debeugny, 1965). In the remaining 12 patients, who showed no abnormality other than the sternal fissure, the operative correction was successful and without complications.

Operative correction of a congenital sternal fissure is therefore quite justifiable even in cases in which there is only paradoxical movement of the anterior chest wall. It must be pointed out, however, that, according to our experience, there may be two additions to the technique described by Sabiston:

(1) the caudal bridge in the sternum probably should be opened before the sternal bars are approximated to prevent a later growth anomaly, as shown by our patient ;

(2) the approximation and fixation by a few stitches of the sternal ends of the sternocleidoclavicular muscles may prevent a later lung hernia through the thoracic outlet (Daum and Heiss, 1970).

TIMING THE OPERATION When there are vital indications, such as attacks of tachycardia and cyanosis, it is obvious that the operation must be performed as soon after birth as possible. In all other cases it is advisable to operate at an early age, when the 'flexibility' of the chest wall

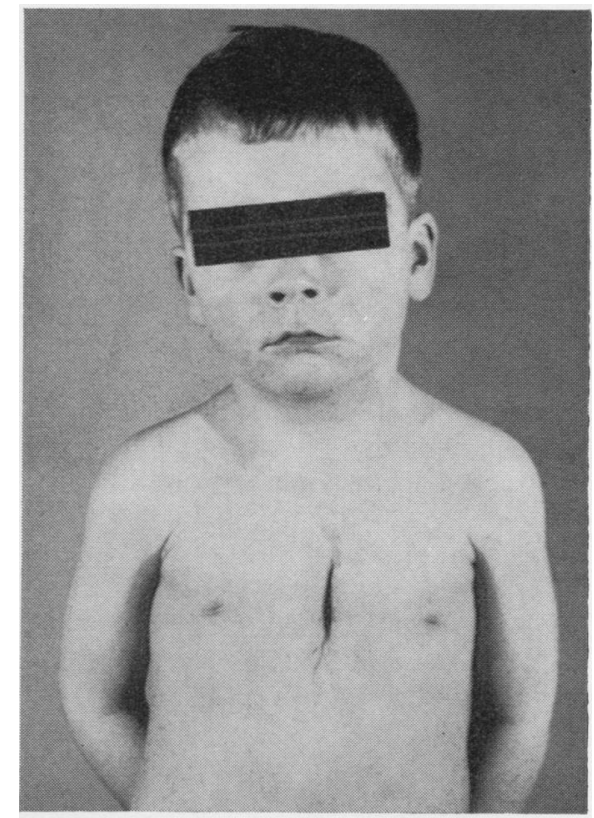

FIG. 12. Two years after operation. 
skeleton is at its maximum. In these cases, however, it is unnecessary to set a time limit because both Sabiston (1958) and Chang and Davis (1966) have demonstrated that correction of a congenital sternal fissure is still quite feasible in patients aged up to 4 years. Our own experience indicates that it is advisable to split the existing caudal union of the sternum in cases of partial fissure, as shown also by Longino and Jewett (1955). This facilitates approximation of the two sternal halves.

\section{CONCLUSION}

A congenital cleft sternum is a rare anomaly which is probably caused by a disturbance in the fusion of the suprasternal structures, the precostal process and the two sternal bands. This non-fusion causes a defect in the skeleton of the anterior chest wall which gives rise to paradoxical movement of this wall.

Morphological investigations and experiments have proved that the sternum is formed independently of the ribs. The conclusion that the sternum arises from material of the lateral plate and not from that of the somites (Seno, 1961; Murillo-Ferrol, 1963 ; Pinot, 1969) is not satisfactory, as is elucidated in the discussion.

Surgical correction of this rare anomaly is feasible both in neonates and in slightly older infants. In a number of cases the operation must be performed shortly after birth if there is a vital indication (attacks of tachycardia or cyanosis). It is advisable, in neonates also, to determine the effect of the anomaly on circulation and respiration as exactly as possible by analysis of an arterial as well as a venous blood sample.

In the absence of vital indications it is unnecessary to operate immediately after birth. In fact the indication to operate on these patients is cosmetic.

In patients who show no other anomalies, correction of the sternal fissure is tolerated well. as demonstrated by 12 cases culled from the literature and our own observation.

\section{REFERENCES}

Asp, K., and Sulamaa, M. (1960). On rare congenital deformities of the thoracic wall. Acta chir. scand., 118, 392.

Brandt, W. (1949). Lehrbuch der Embryologie. Karger, Basel.

Burton, J. F. (1947). Method of correction of ectopia cordis. Arch. Surg., 54, 79.
Chang, C. H., and Davis, W. Clayton (1966). Congenital bifie sternum with partial ectopia cordis. Amer. J. Roentgenol., 86 513.

Chen, J. M. (1952a). Studies on the morphogenesis of the mouse sternum. I. Normal embryonic development. J. Anat. (Lond.) 86, 373 .

- (1952b). Studies on the morphogenesis of the mouse sternum II. Experiments on the origin of the sternum and its capacity for self-differentiation in vitro. J. Anat. (Lond.), 86, 387.

- (1953). Studies on the morphogenesis of the mouse sternum III. Experiments on the closure and segmentation of the sternab bands. J. Anat. (Lond.), 87, 130.

Daum, R., and Heiss I(1970). Zur operativen Korrektur ange=-1 borener Sternum-spalten. XV. Thoraxchir. Arbeitstagungç Bad Nauheim, Feb. 1970. Eggeling, H. (1906). Clavicula, Praeclavium, Halsrippen und Manus
brium sterni. Anat. Anz., 29, 99 .

Fell, H. B. (1939). The origin and developmental mechanics of the avian sternum. Phil. Trans. B, 229B, 407.

Gladstone, R. J., and Wakeley, C. P. G. (1932). The morphology of the sternum and its relation to the ribs. J. Anat. (Lond.), 66, 508

Greig, D. M. (1926). Cleft-sternum and ectopia cordis. Edinb. med J., 33, 480

Groot, J. W. C. de, and Huizinga, J. C. (1954). Fissura stern congenita (in Dutch). Maandschr. Kindergeneesk., 22, 203.

Hommes, J. H. (1921). Over de ontwikkeling van de clavicula ere het sternum van vogels en zoogdieren. Diss. Groningen.

Ingelrans, P., and Debeugny, P. (1965). Observation de bifidité dis sternum associé à une angiomatose trachéale. Ann. Chir. infant. $\overrightarrow{0}$ 6, 123.

Jewett, T. C., Butsch, W. L., and Hug, H. R. (1962). Congenitab bifid sternum. Surgery., 52, 932.

Keeley, J. L., Schairer, A. E., and Brosnan, J. J. (1960). Failure of sternal fusion: bifid sternum. Arch. Surg., 81, 641.

Klassen, K. (1949). Discussion on Maier and Bortone: Failure of sternal fusion. J. thorac. Surg., 18, 859.

Klima, M. (1968). Early development of the human sternum an the problem of homologization of the so-called suprasternap structures. Acta anat. (Basel), 69, 473.

Longino, L. A., and Jewett, T. C. (1955). Congenital bifid sternum Surgery, 38, 610 .

Magan, M. G. (1949). A case of fissura sterni congenita completa? Brit. J. Radiol., 22, 286.

Maier, H. C., and Bortone, F. (1949). Complete failure of sterna? fusion with herniation of pericardium. J. thorac. Surg., 18 851 .

Martin, L. W., and Helmsworth, J. A. (1962). The management of congenital deformities of the sternum. J. Amer. med. Ass.. 1799 82.

Meissner, F. (1964). Fissura sterni congenita. Zbl. Chir., 89, 1832X

Müller, C. (1906). Zur Entwicklung des menschlichen Brustkorbes음 Gegenbaurs Morph. Jb., 35, 591 .

Murillo-Ferrol, N. L. (1963). About the forming material of the ribs and sternum. An experimental analysis in the chick embryoO An. Desarrollo, 11, 391.

Patten, B. M. (1968). Human Embryology, 3rd ed. Blakiston, New York.

Pfeiffer, K. (1956). Variationen und Anomalien des Brustbeines sowie Hinweise zu deren Entwicklung. Fortschr. Röntgenstr $85,663$.

Pinot, M. (1969). Etude expérimentale de la morphogenèse de lä cage thoracique chez l'embryon de Poulet: mécanismes ef origine du materiel. J. Embryol. exp. Morph., 21, 149.

Reiter, A. (1942). Die Frühentwicklung des Brustkorbes und deß Brustbeines beim Menschen. Z. Anat. Entwickl.-Gesch., 111 676.

Sabiston, D. C. (1958). The surgical management of congenital bifio sternum with partial ectopia cordis. J. thorac. Surg., 35, 118

Seno, T. (1961). The origin and evolution of the sternum. Anato Anz., 110, 97 Szenes, A. (1922). Ciber die Fissura sterni und ihre Entstehung
Arch. Klin. Chir., 119, 116.

Thompson, H. T. (1961). Failure of sternal fusion with herniation of the pericardium. Thorax, 16, 386.

Whitehead, R. H., and Waddell, J. A. (1911). The early developmen? of the mammalian sternum. Amer. J. Anat., 12, 89 . 